\title{
Analysis of Th17 and Tc17 Frequencies and Antiviral Defenses in Gut-Associated Lymphoid Tissue of Chronic HIV-1 Positive Patients
}

\author{
Gabriella d'Ettorre, ${ }^{1,2}$ Giancarlo Ceccarelli, ${ }^{1,2}$ Mauro Andreotti, ${ }^{3}$ Carla Selvaggi, ${ }^{2,4}$ \\ Noemi Giustini, ${ }^{1,2}$ Sara Serafino, ${ }^{1,2}$ Ivan Schietroma, ${ }^{1,2}$ Giuseppe Nunnari, ${ }^{5}$ \\ Guido Antonelli, ${ }^{2,4}$ Vincenzo Vullo, ${ }^{1}$ and Carolina Scagnolari ${ }^{2,4}$ \\ ${ }^{1}$ Department of Public Health and Infectious Diseases, University of Rome "Sapienza", 00185 Rome, Italy \\ ${ }^{2}$ Pasteur Institute-Cenci Bolognetti Foundation, 00161 Rome, Italy \\ ${ }^{3}$ Department of Therapeutic Research and Medicines Evaluation, Italian Institute of Health, 00161 Rome, Italy \\ ${ }^{4}$ Department of Molecular Medicine, Laboratory of Virology, "Sapienza" University of Rome, 00185 Rome, Italy \\ ${ }^{5}$ Department of Clinical and Molecular Biomedicine, Division of Infectious Diseases, University of Catania, 95122 Catania, Italy
}

Correspondence should be addressed to Giancarlo Ceccarelli; giancarlo.ceccarelli@uniromal.it

Received 27 February 2015; Revised 7 May 2015; Accepted 21 May 2015

Academic Editor: Jianfei Yang

Copyright (C) 2015 Gabriella d'Ettorre et al. This is an open access article distributed under the Creative Commons Attribution License, which permits unrestricted use, distribution, and reproduction in any medium, provided the original work is properly cited.

\begin{abstract}
The complex relationship between both the Th1/Th17 and Tc1/Tc17 axis and innate defences in the intestinal mucosa during HIV-1 infection has not been well characterized. This study examined the frequency, phenotype, and functional status of T cell populations in the gut-associated lymphoid tissue and peripheral blood of virologically suppressed HIV-1-infected patients on therapy, focusing on the Thl, Th17, Tcl, and Tc17 cell subsets. We found a persistent immune cell activation (CD38 and HLADR expression) into the GALT despite the higher levels of Th17 and Tc17 in respect to peripheral blood. An upregulation of type I IFN response in GALT compared to the peripheral blood compartment was also recorded. Furthermore, IFN- $\alpha / \beta$ levels were negatively related to the frequencies of Thl naïve cells and Tcl cell subsets (naïve, central memory, and effector memory) in the GALT. In contrast, no relationships between type I IFN response and Thl or Tcl cell subsets in peripheral blood compartment and between IFN- $\alpha / \beta$ and Th17/Tc17 in both GALT and peripheral blood district were recorded. These data indicate that prolonged antiretroviral treatment improves GALT immune function despite the persistence of immune activation and type I IFN response in chronic HIV-1 positive patients.
\end{abstract}

\section{Introduction}

IL-17-producing $\mathrm{CD}^{+}{ }^{+} \mathrm{T}$ cells (Th17) are known to regulate the permeability of gut mucosa and microbial translocation. $\mathrm{T}$ helper type 17 cells mediate a variety of inflammatory reactions through their selective secretion of IL-17A, IL-17F, and IL-22.

Recent studies have demonstrated that Th17 cells are depleted during HIV/SIV infections, suggesting that cell depletion may accelerate the progression to AIDS $[1,2]$. The early initiation of antiretroviral therapy (ART) has been reported to preserve the number and function of Th17 with consequent control of HIV-related immune activation [13]. Accordingly, HIV-1-infected individuals receiving ART undergo effective $\mathrm{CD} 4^{+} \mathrm{T}$ cell restoration and this is associated with enhanced $\mathrm{CD} 4^{+}$Th17 cell accumulation without complete restoration [4]. Furthermore, although IL-17secreting $\mathrm{CD}^{+}{ }^{+}$and $\mathrm{CD}^{+}{ }^{+} \mathrm{T}$ cells have been reported, very little is known about the $\mathrm{CD}^{+}{ }^{+} \mathrm{T}$ subset in HIV-1 infection and its relationship with immune response activation.

A variety of signals can block Th17 commitment including IFN- $\gamma$, IL-4, and IL-12 [5]. Furthermore, Harrington 
et al. showed that the $\mathrm{CD} 4^{+}$T cell effector cytokine IFN- $\gamma$ potently suppressed the development of the IL-17-producing effector T cells from naïve $\mathrm{CD} 4^{+}$precursor cells, providing a mechanism by which the Thelper type 1 (Thl) developmental program "antagonizes" the Thl7 developmental program and contributes to lineage divergence. Interestingly, IFN- $\alpha / \beta$ was also demonstrated to have a negative impact on Th17 development in mice [6], recently extended to human Th17 cells [7]. Therefore, the dysregulated Th17 response during HIV-1 infection could in part be explained by the reported ability of type I IFN to suppress Th17 development $[8,9]$. In this regard, the mucosal antiviral responses appeared to be largely type I IFN-driven and included factors that inhibit HIV-1 budding (tetherin/BST2) and infectivity (APOBEC3G) [10]. However, no studies on the relationships between Th17 and type I IFN response have been performed so far. Besides the well-established detrimental effects of type IFN in chronic HIV-1-infected patients, this complex family of cytokines also seems to regulate the effector and memory $\mathrm{T}$ cell functions $[5,11,12]$.

To our knowledge, this is the first study to evaluate the relationship between type I IFN activation and IFN- $\gamma$ or IL17A expressing $\mathrm{CD}^{+} \mathrm{CD}^{+}$or $\mathrm{CD}^{+} \mathrm{CD}^{+} \mathrm{T}$ cell subsets in the gut-associated lymphoid tissue (GALT) of HIV-1-infected subjects. The objectives of the study were to compare the gene expression of IFN- $\alpha$, IFN- $\beta$, and IFN receptor (R1) between peripheral blood cells and GALT collected from HIV-1infected patients who achieved a virological suppression in response to ART therapy. In addition, the relationships between activation of type I IFN response and IFN- $\gamma$ or IL17A-producing $\mathrm{CD}^{+}$or $\mathrm{CD}^{+}$(Tc17) $\mathrm{T}$ cell subsets (naïve, central memory, and effector memory) were evaluated.

\section{Methods}

2.1. Patients. From May to July 2014, ten HIV-1 positive patients successfully treated with ART were recruited at the Division of Infectious Diseases, Department of Public Health and Infectious Diseases, Hospital of "Sapienza" University of Rome (Italy).

The study was approved by the institutional review board (Department of Public Health and Infectious Diseases, "Sapienza" University of Rome and the Ethics Committee of Umberto I General Hospital, Rome). All study participants gave written informed consent.

2.2. Laboratory Procedures, Data Collection, and Analysis Sampling. Patients were sampled for peripheral blood $(20 \mathrm{~mL})$ and underwent endoscopic procedures. Colonic washing was carried out by PEG administration 24 hours before the examination. The endoscopic procedure was performed with conscious sedation (midazolam $5 \mathrm{mg} / \mathrm{iv}$ ) using large cup forceps (Radial Jaw 4, Boston Scientific, Natick, Massachusetts, USA). All HIV-1 positive patients underwent a total colonoscopy and retrograde ileoscopy for at least $10 \mathrm{~cm}$ of distal ileum with conventional or slim scope (model CF or PCF-160 AI, Olympus Medical Europe GmbH, Hamburg, Germany). We obtained specimens (2 biopsies from each site) from the terminal ileum, cecum, ascending, transverse, and descending colon. T cell phenotype and activation markers were analyzed on freshly isolated peripheral blood mononuclear cells (PBMCs) and lamina propria lymphocytes (LPLs) and T cell phenotype and cytokine expression were evaluated after overnight cell culture. One aliquot each of PBMCs and LPLs was stored as dried pellets for RNA extraction.

2.3. Specimen Processing. Peripheral blood samples were collected in tubes containing ethylenediaminetetraacetic acid and plasma were previously separated by centrifugation. Blood was processed to obtain PBMCs by Ficoll gradient centrifugation (Lympholyte, Cedarlane Labs, Hornby, Ontario, Canada). Gut biopsies from each intestine site were pooled and processed. Briefly, biopsies collected in RPMI 1640 were washed twice with EDTA wash media, resuspended, and incubated for 1 hour at room temperature in EDTA solution $5 \mathrm{mM}$. Supernatant containing intraepithelial lymphocytes was removed, and biopsies were digested by 1 hour incubation at $37^{\circ} \mathrm{C}$ with $1 \mathrm{mg} / \mathrm{mL}$ collagenase (Sigma-Aldrich, Milan, Italy) and 1.5 U DNAse I (Sigma-Aldrich, Milan, Italy), allowing the isolation of LPLs that were filtered through a $70 \mu \mathrm{m}$ cell strainer.

2.4. Cell Cultures. PBMCs and LPLs were seeded at concentrations of $2 \times 10^{6}$ cells $/ \mathrm{mL}$ and $1.5 \times 10^{6}$ cells $/ \mathrm{mL}$, respectively, with RPMI media $+20 \%$ heat inactivated fetal bovine serum (FBS) and cultured overnight at $37^{\circ} \mathrm{C}$ and $5 \% \mathrm{CO}_{2}$ in the presence of medium alone or phorbol myristyl acetate (PMA) (3 ng/mL, Sigma Aldrich, Milan Italy) and ionomycin $(1 \mu \mathrm{g} / \mathrm{mL}$, Sigma Aldrich, Milan, Italy). BD GolgiStop (Becton Dickinson, San Jose, CA, USA) was added to all culture conditions. Cells were collected, washed, and stained for $\mathrm{T}$ cell phenotype and cytokine expression.

2.5. Monoclonal Antibody and T Cell Phenotyping. Phenotype and activation were evaluated by multiparameter flow cytofluorimetric analysis on freshly isolated PBMCs and LPLs by the following anti-human monoclonal antibodies: CD3-PerCP, CD4 ${ }^{+}$-APC-Vio770, CD8 ${ }^{+}$-FITC, CD45RO-PEVio770, CD27-VioBlue, CD38-APC, and HLA-DR-PE (Miltenyi Biotec, Bergisch Gladbach, Germany).

Cultured cells were fixed, permeabilized (BD Cytofix/ Cytoperm, Becton Dickinson, San Jose, CA, USA), and stained with combinations of fluorochrome-labeled monoclonal antibodies: CD3-PerCP, CD4-APC-Vio770, CD8FITC, CD45RO-PE-Vio770, CD27-VioBlue, IFN- $\gamma$-APC, and IL-17A-PE (Miltenyi Biotec, Bergisch Gladbach, Germany). $\mathrm{CD}^{+} \mathrm{CD}^{+}$cells expressing IFN- $\gamma$ or IL-17A were identified as Thl and Th17, respectively; $\mathrm{CD}^{+} \mathrm{CD}^{+}$cells expressing IFN- $\gamma$ or IL-17A were identified as Tc1 and Tc17, respectively; $\mathrm{CD}^{+} \mathrm{CD}^{+}$and $\mathrm{CD}^{+}{ }^{+} \mathrm{CD} 8^{+}$expressing both IFN- $\gamma$ and IL-17 were defined as $\mathrm{CD} 4^{+} \mathrm{DP}$ and $\mathrm{CD} 8^{+} \mathrm{DP} \mathrm{T}$ cells, respectively.

$\mathrm{T}$ cell subpopulations were identified according to the following phenotypic combinations: $\mathrm{CD}_{2} 7^{+} \mathrm{CD} 45 \mathrm{RO}-$ (naïve), $\mathrm{CD}^{2} 7^{+} \mathrm{CD} 45 \mathrm{RO}^{+}$(central memory), and $\mathrm{CD} 27^{-} \mathrm{CD} 45 \mathrm{RO}^{+} \mathrm{CD} 4^{+}$(effector memory) cells [13].

Acquisitions were performed on Miltenyi Biotec flow cytometer-MACSQuant Analyzer (8 fluorescence channels, 3 


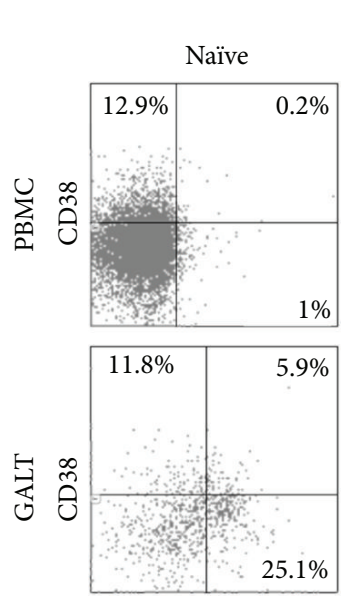

HLA-DR
$\mathrm{CD} 3^{+} \mathrm{CD} 4^{+}$
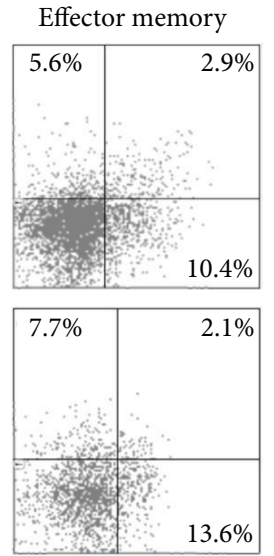

HLA-DR
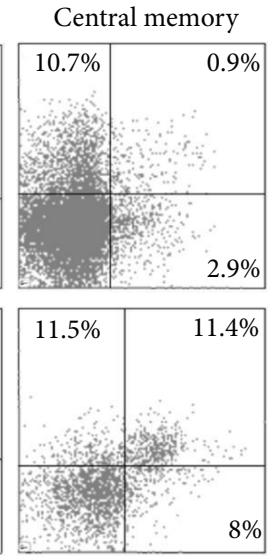

HLA-DR
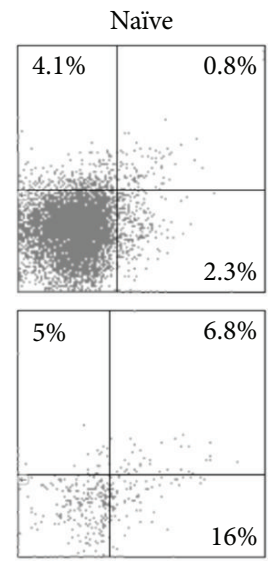

HLA-DR
$\mathrm{CD}^{+}{ }^{+} \mathrm{CD} 8^{+}$
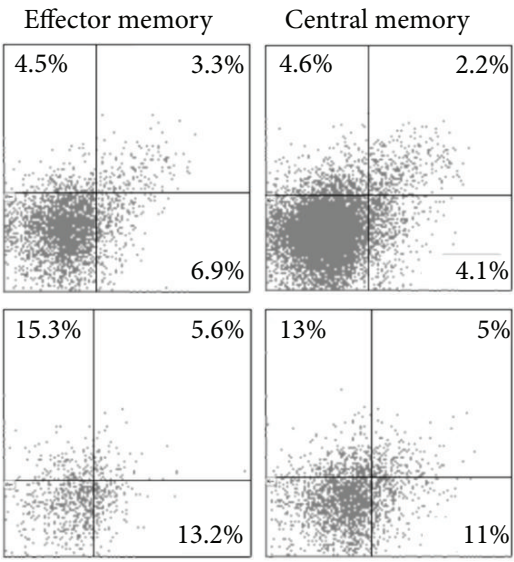

HLA-DR

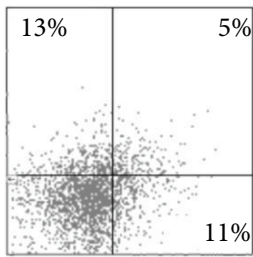

HLA-DR

(a)

$\mathrm{CD} 3^{+} \mathrm{CD} 4^{+}$
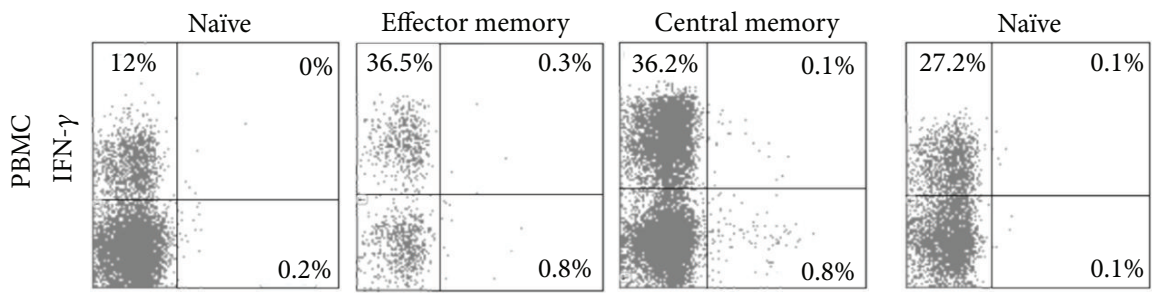

$\mathrm{CD}^{+} \mathrm{CD}^{+}$

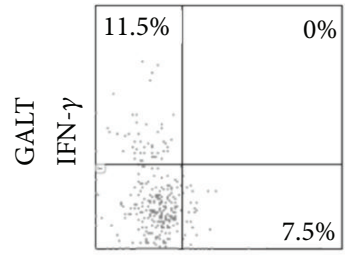

IL-17A

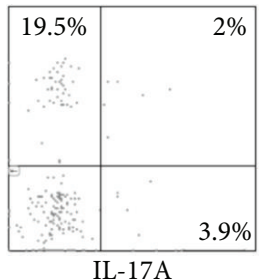

IL-17A

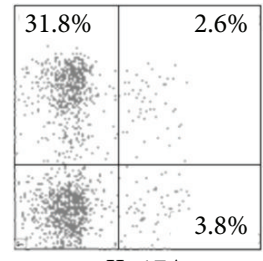

IL-17A

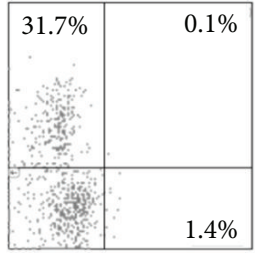

IL-17A
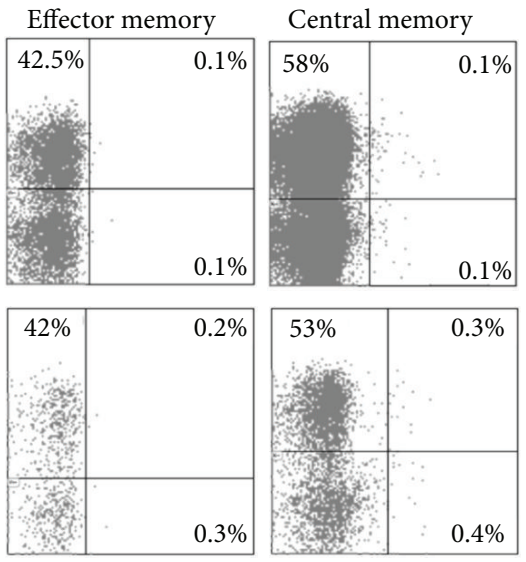

IL-17A

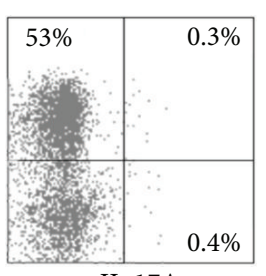

IL-17A

(b)

FIGURE 1: Activation markers, IFN- $\gamma$ and IL-17A expression in CD $4^{+}$and $\mathrm{CD} 8^{+} \mathrm{T}$ cells subsets in blood and in gut. Panel (a): representative flow cytometry plots outlining CD38 and HLA-DR expression on naïve, effector, and central memory CD $4^{+}$and CD $8^{+}$lymphocytes derived from peripheral blood mononuclear cells (PBMCs) and gut-associated lymphoid tissue (GALT). Panel (b): representative flow cytometry plots outlining IFN- $\gamma$ and IL-17A intracitoplasmatic expression on naïve, effector, and central memory CD $4^{+}$(Th1 and Th17) and CD $8^{+}$(Tc1 and Tc17) lymphocytes derived from PBMCs and GALT.

lasers) and data were analyzed using MACSQuantify software 2.5 (Miltenyi Biotec, Bergisch Gladbach, Germany) with the same gating strategy applied to all samples.

At least 100,000 and 10,000 events in the $\mathrm{CD}^{+}$lymphocyte gate were analyzed for PBMCs and LPLs, respectively. Representative flow cytometry plots outlining activation markers, IFN- $\gamma$ and IL-17A expression in $\mathrm{CD}^{+}$and $\mathrm{CD} 8^{+}$ $\mathrm{T}$ cells subsets in blood (PBMCs) and in gut (GALT), are reported in Figure 1.

2.6. Virological Analysis. Plasma samples were analyzed for HIV-1 RNA copy number by VERSANT HIV-1 RNA 1.0 kPCR assay (Siemens) with a detection limit of 37 copies/ $\mathrm{mL}$.
2.7. TaqMan-Based Real-Time RT-PCR Assays for $m R N A$ Expression. Quantitative real-time PCR for IFN- $\alpha$, IFN$\beta$, and IFNR1 was carried out with the LightCycler 480 instrument (Roche, Basel, Switzerland). Briefly, total RNA was extracted from PBMCs and LPLs using the RNeasy Plus Universal Tissue Mini Kit (Invitrogen, Carlsbad, CA, USA) and reverse transcribed using the High-Capacity cDNA Reverse Transcription Kit (Applied Biosystem), according to the manufacturer's protocol. Primers and probes for each gene were added to the Probes Master Mix (Roche, Basel, Switzerland) at 500 and $250 \mathrm{nM}$, respectively, in a final volume of $20 \mu \mathrm{L}$. The housekeeping gene $\beta$-glucuronidase [14] was used as an internal control. Gene expression values were calculated by the comparative Ct method. The primers and 
TABLE 1: Th17 and Th1 frequencies in peripheral blood and gut-associated lymphoid tissue (GALT) samples collected from HIV-1-infected patients $(n=10)$ who achieved virological suppression in response to ART therapy.

\begin{tabular}{lccc}
\hline Frequencies & GALT & Peripheral blood & $p$ values \\
\hline Th17 cells (median/range) & $1.06 / 0.21-3.66$ & $0.26 / 0.00-0.67$ & $p=\mathbf{0 . 0 0 7}$ \\
Th1 cells (median/range) & $5.71 / 0.23-25.19$ & $0.16 / 0.01-28.72$ & $p=0.059$ \\
CD4 DP T cells (median/range) & $0.17 / 0.0-2.28$ & $0.005 / 0.0-0.12$ & $\mathbf{p}=\mathbf{0 . 0 1 7}$ \\
Naïve Th17 cells (median/range) & $1.19 / 0.0-8.73$ & $0.09 / 0.0-0.36$ & $\mathbf{p}=\mathbf{0 . 0 0 8}$ \\
Naïve Th1 cells (median/range) & $1.01 / 0.23-11.56$ & $0.04 / 0.0-13.0$ & $p=0.79$ \\
Naïve CD4 DP T cells (median/range) & $0.0 / 0.0-0.49$ & $0.0 / 0.0-0.05$ & $p=0.69$ \\
Central memory Th17 cells (median/range) & $0.935 / 0.0-3.87$ & $0.24 / 0.00-1.19$ & $\mathbf{p}=\mathbf{0 . 0 1 3}$ \\
Central memory Th1 cells (median/range) & $7.65 / 0.19-33.14$ & $0.22 / 0.0-36.21$ & $p=0.169$ \\
Central memory CD4 ${ }^{+}$DP T cells (median/range) & $0.15 / 0.0-3.15$ & $0.01 / 0.0-0.14$ & $\mathbf{p}=\mathbf{0 . 0 1 1}$ \\
Effector memory Th17 cells (median/range) & $0.48 / 0.0-4.05$ & $0.21 / 0.00-1.61$ & $\mathbf{p}=\mathbf{0 . 0 3 7}$ \\
Effector memory Th1 cells (median/range) & $3.28 / 0.00-19.53$ & $0.33 / 0.0-47.04$ & $0.0 / 0.0-0.34$ \\
Effector memory CD4 ${ }^{+}$DP T cells (median/range) & $0.16 / 0.0-2.03$ & $\mathbf{p}=\mathbf{0 . 0 2 8}$ \\
\hline
\end{tabular}

${ }^{*}$ Wilcoxon test for paired samples was used to compare Thl7 and Thl frequencies in peripheral blood and GALT. Significant values are highlighted in bold.

probe sequences used for IFN- $\alpha$ (Hs. PT.58.24294810.g), IFN$\beta$ (Hs. PT.58.39481063.g), and IFNR1 (Hs. PT.58.25402720.g) were purchased from Integrated DNA Technologies (IDT), Iowa, USA.

2.8. Statistical Analysis. Statistical analyses and graphic presentation were done using SPSS software, version 20.00 (IBM, Somers, NY, USA) on data obtained from PBMC and gut samples of $10 \mathrm{HIV}-1$ positive patients. In particular, peripheral and intestinal districts were compared by Wilcoxon test for paired samples. Results are given as medians, ranges, and percentages. Linear regression with Spearman's correlation coefficient was used to evaluate correlations between quantitative variables. Differences were considered statistically significant when $p<0.05$.

\section{Results}

3.1. Participant Characteristics. All study participants were Caucasian men with a median age of 42 years (22-53 years). They initiated therapy during chronic infection and had been on ART for a median of 6 years (IQR, 1.75 to 16.25 years); pretherapy median $\mathrm{CD} 4^{+}$cell count was 255 cells $/ \mathrm{mm}^{3}$ (IQR, 42.75 to 406.75 cells $/ \mathrm{mm}^{3}$ ), and HIV-1 RNA copies median value was $5.0 \mathrm{Log} / \mathrm{mL}$ (IQR, 4.81 to $5.61 \mathrm{Log} / \mathrm{mL}$ ). All subjects had been virologically suppressed ( $<37$ HIV-1 RNA copies $/ \mathrm{mL}$ ) for at least 1 year at the time of gut biopsy; their median $\mathrm{CD} 4^{+}$cell count was 674 cells $/ \mathrm{mm}^{3}$ (IQR, 564 to 824 cells $/ \mathrm{mm}^{3}$ ).

3.2. Th17 and Th1 Frequencies in Peripheral Blood and GALT. We compared the Th17 and Th1 frequencies in peripheral blood and GALT samples collected from treated HIV-1infected patients who had shown a virological response to ART therapy. As seen from Table 1, the median frequencies of Th17, naïve Th17, and CD4 ${ }^{+}$DP T cells were higher in GALT than in peripheral blood (resp., $p=0.007, p=0.017$, and $p=0.008)$. Furthermore, a trend toward a higher median frequency of Th1 in GALT than in peripheral blood was observed ( $p=0.059$, Table 1$)$. Similar results were obtained comparing the frequencies of central memory and effector memory $\mathrm{CD}^{+} \mathrm{T}$ cell subpopulations in the peripheral and GALT compartments. In particular, the median frequencies of both central and effector memory Th17 cell subsets were significantly higher in GALT than in peripheral blood ( $p=$ 0.013 and $p=0.037$, resp.). The individual values of Th17 frequencies for naïve and memory subsets are plotted in Figure 2. The same trend was observed for the central and effector memory Th1 cell subsets although the differences did not reach statistical significance (Table 1). Lastly, we found that the median frequencies of both central and effector memory $\mathrm{CD}^{+}$DP T cells were statistically higher in GALT than in peripheral blood (resp., $p=0.011$ and $p=0.028$, Table 1).

\subsection{Tc17 and Tc1 Frequencies in Peripheral Blood and GALT.} Having observed a higher frequency of Th17/Th1 cells in the GALT of HIV-1-infected patients compared to that measured in the peripheral blood, we analyzed the Tc17 and Tc1 frequencies in the same compartments. As seen from Table 1, the median frequencies of Tc17, naïve $\mathrm{Tcl}$, and $\mathrm{CD}^{+} \mathrm{DP} \mathrm{T}$ cells were significantly higher in GALT than in peripheral blood (resp., $p=0.018, p=0.017$ and $p=0.005$, Table 2). A trend towards a higher median frequency of naïve Tc17 cells in GALT than in peripheral blood was also found ( $p=$ 0.059 , Table 2). In contrast, no statistical differences were observed for the frequencies of Tcl, central memory Tcl7, central memory Tcl, or central memory $\mathrm{CD}^{+}$DP T subsets between GALT and peripheral blood. Furthermore, we found that the median frequencies of effector memory Tcl7 cells were significantly higher in GALT than in peripheral blood ( $p=0.035$, Table 2$)$ while the median frequencies of effector memory $\mathrm{Tcl}$ and $\mathrm{CD}^{+} \mathrm{DP} \mathrm{T}$ cells were similar in the two compartments analyzed. The individual values of Tc17 frequencies for naïve and memory subsets are plotted in Figure 2. 


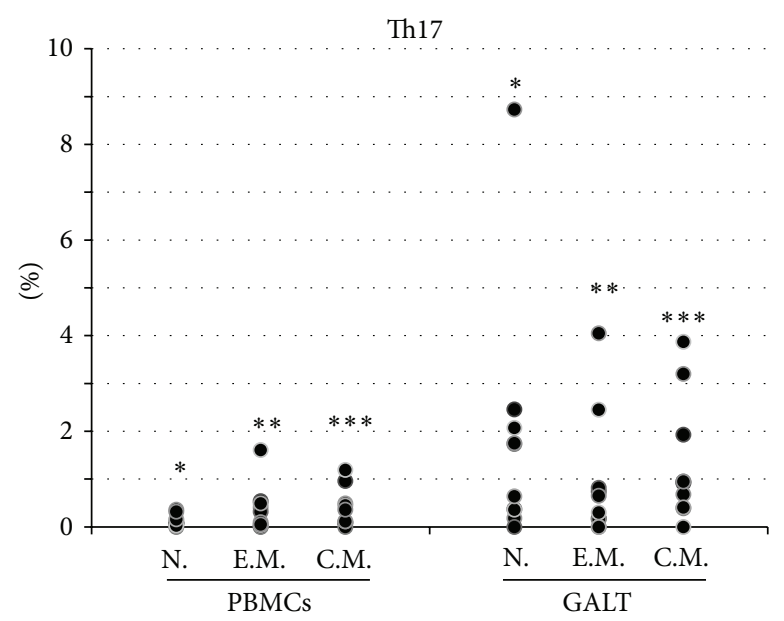

(a)

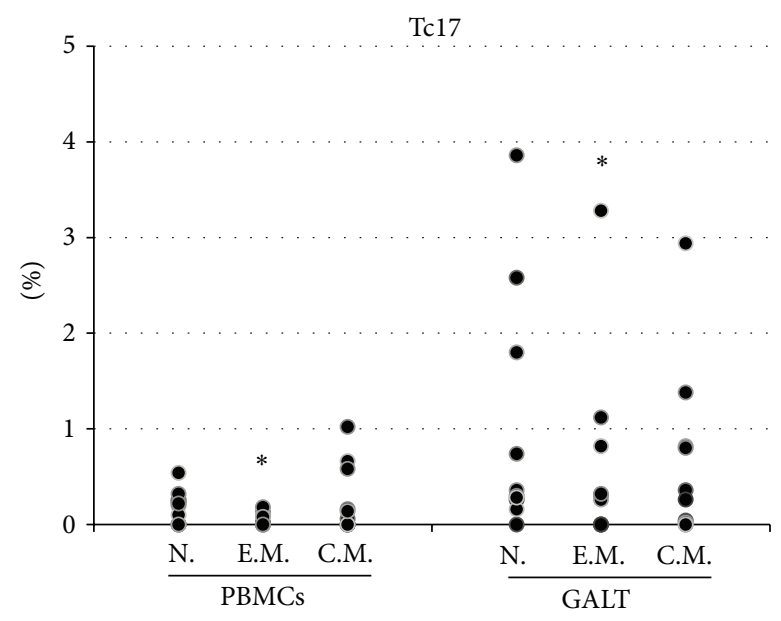

(b)

FIGURE 2: Th17 and Tc17 frequencies in lymphocytes subsets derived from peripheral blood mononuclear cells (PBMC) and gut-associated lymphoid tissue (GALT). Dot plots represent the frequencies of Th17 and Th1 cells in naïve (N), effector memory (E.M.), and central memory (C.M.) $\mathrm{CD}^{+}$and $\mathrm{CD}^{+}$in PBMC and in GALT (Wilcoxon test for paired samples $*, * *$, and $* * *=p<0.05$ ).

TABLE 2: Frequencies of Tc17 and Tc1 in peripheral blood and gut-associated lymphoid tissue (GALT) samples collected from HIV-1-infected patients $(n=10)$ who achieved virological suppression in response to ART therapy.

\begin{tabular}{|c|c|c|c|}
\hline Frequencies & GALT & Peripheral blood & $p$ values \\
\hline Tc17 cells (median/range) & $0.21 / 0.00-1.50$ & $0.03 / 0.00-0.1$ & $\mathrm{p}=\mathbf{0 . 0 1 8}$ \\
\hline Tc1 cells (median/range) & $10.59 / 0.32-56.34$ & $0.36 / 0.0-58.24$ & $p=0.114$ \\
\hline $\mathrm{CD}^{+}$DP T cells (median/range) & $0.095 / 0.0-1.16$ & $0.005 / 0.0-0.11$ & $\mathbf{p}=\mathbf{0 . 0 1 7}$ \\
\hline Naïve Tc17 cells (median/range) & $0.17 / 0.0-1.9$ & $0.11 / 0.0-0.27$ & $p=0.059$ \\
\hline Naïve Tc1 cells (median/range) & $6.24 / 0.37-41.74$ & $0.49 / 0.0-31.61$ & $\mathrm{p}=0.005$ \\
\hline Naïve CD8 ${ }^{+}$DP T cells (median/range) & $0.0 / 0.0-0.41$ & $0.01 / 0.0-0.07$ & $p=0.262$ \\
\hline Central memory Tc17 cells (median/range) & $0.16 / 0.0-1.47$ & $0.05 / 0.00-0.51$ & $p=0.169$ \\
\hline Central memory Tc1 cells (median/range) & $15.38 / 0.52-58.75$ & $1.36 / 0.0-72.9$ & $p=0.386$ \\
\hline Central memory CD8 ${ }^{+}$DP T cells (median/range) & $0.09 / 0.0-1.17$ & $0.04 / 0.0-1.17$ & $p=0.063$ \\
\hline Effector memory Tc17 cells (median/range) & $0.14 / 0.0-1.64$ & $0.025 / 0.00-0.09$ & $\mathrm{p}=\mathbf{0 . 0 3 5}$ \\
\hline Effector memory Tcl cells (median/range) & $10.27 / 0.27$ & $0.45 / 0.0-83.54$ & $p=0.720$ \\
\hline Effector memory CD8 ${ }^{+}$DP T cells (median/range) & $0.00 / 0.0-1.24$ & $0.00 / 0.00-1.64$ & $p=0.721$ \\
\hline
\end{tabular}

${ }^{*}$ Wilcoxon test was used to compare Tc17 and Tcl frequencies in peripheral blood and GALT. Significant values are highlighted in bold.

3.4. $\mathrm{CD}^{+}$and $\mathrm{CD}^{+} \mathrm{T}$ Cell Activation in Peripheral Blood and GALT. To estimate the activation of T cells in peripheral blood and intestine, we analyzed the frequencies of $\mathrm{CD}^{+}$and $\mathrm{CD}^{+}{ }^{+} \mathrm{T}$ cells expressing HLA-DR, CD38 and coexpressing CD38 and HLA-DR. The results are reported in Figure 3. The median frequencies of $\mathrm{CD}^{+}$cells expressing HLA-DR and coexpressing HLA-DR and CD38 were higher in GALT than in peripheral blood (13.55 versus 4.38: $p=0.005$, and 4.85 versus 1.35: $p=0.005$ resp.); these differences seemed to be driven by HLA-DR, as no statistically significant differences were observed with CD38 alone (10.6 versus $14.9, p=$ 0.203). Similar statistical differences in expression of HLADR antigen between intestine and peripheral blood were also observed in the central memory and naive subsets of $\mathrm{CD} 4^{+}$ $\mathrm{T}$ cells (14.85 versus 1.87: $p=0.005$, and 12.15 versus 4.40 : $p=0.005$ resp.). Furthermore, we found that the frequencies of $\mathrm{CD}^{+} \mathrm{T}$ cells expressing CD38 antigen were significantly higher in GALT than in peripheral blood within the effector memory and central memory subpopulations (9.51 versus 3.26: $p=0.017$, and 15.24 versus 6.61: $p=0.047$, resp.). By contrast, within the $\mathrm{CD}^{+} \mathrm{T}$ cells with naïve phenotype, the expression of CD38 antigen was higher in peripheral blood than in intestine (24.05 versus 13.58: $p=0.028$ ). Moreover, median frequencies of naïve and central memory $\mathrm{CD}_{4}^{+} \mathrm{T}$ cells coexpressing HLA-DR and CD38 were higher in GALT than in peripheral blood (8.87 versus 0.88: $p=0.005$, and 5.12 versus 1.24: $p=0.005$, resp.).

As far as the analysis of $\mathrm{CD}^{+} \mathrm{T}$ cells expressing HLADR and CD38 and coexpressing CD38 and HLA-DR is concerned, the frequencies of $\mathrm{CD}^{+} \mathrm{T}$ cells expressing CD38 antigen were higher in gut than in peripheral blood $(9.50$ versus 2.86: $p=0.028)$; the central memory and effector memory $\mathrm{CD}^{+} \mathrm{T}$ subpopulations also expressed more CD38 in intestine than in peripheral blood (7.64 versus 3.73: $p=$ 

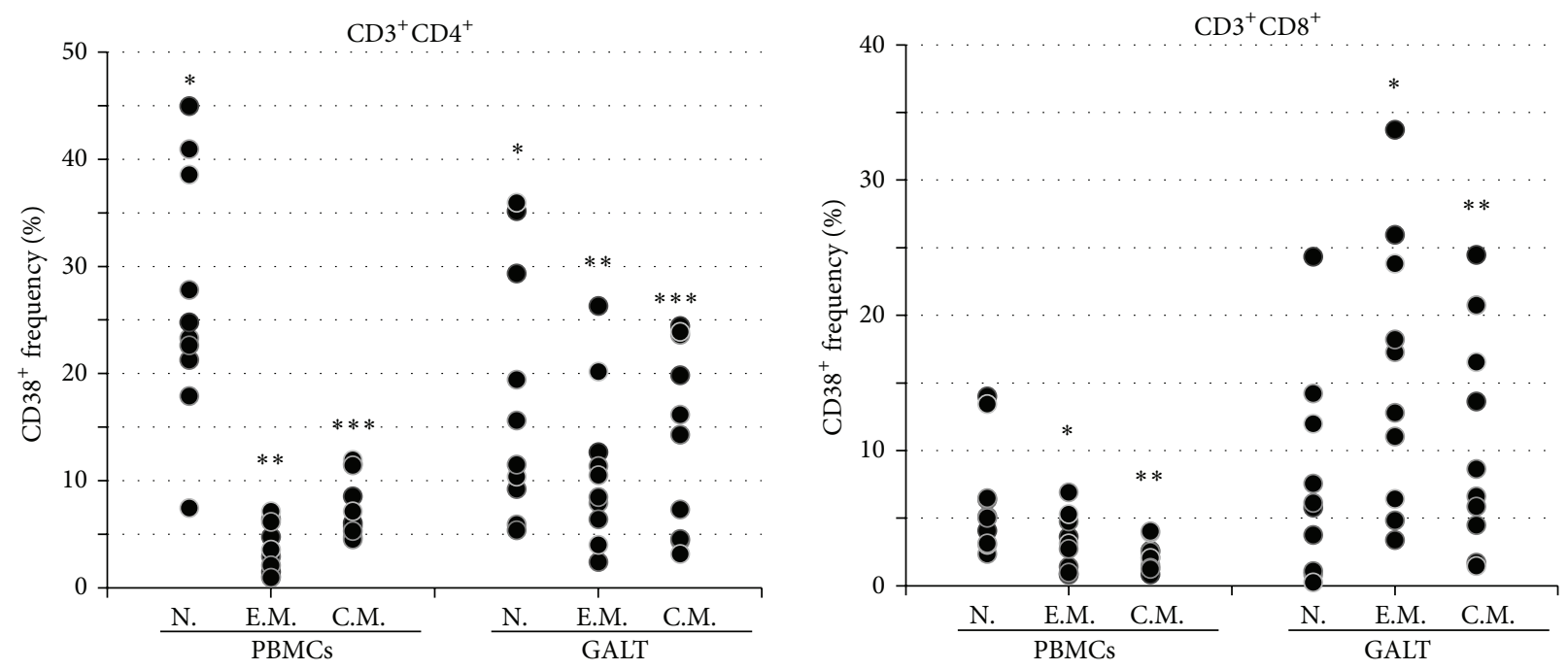

(a)
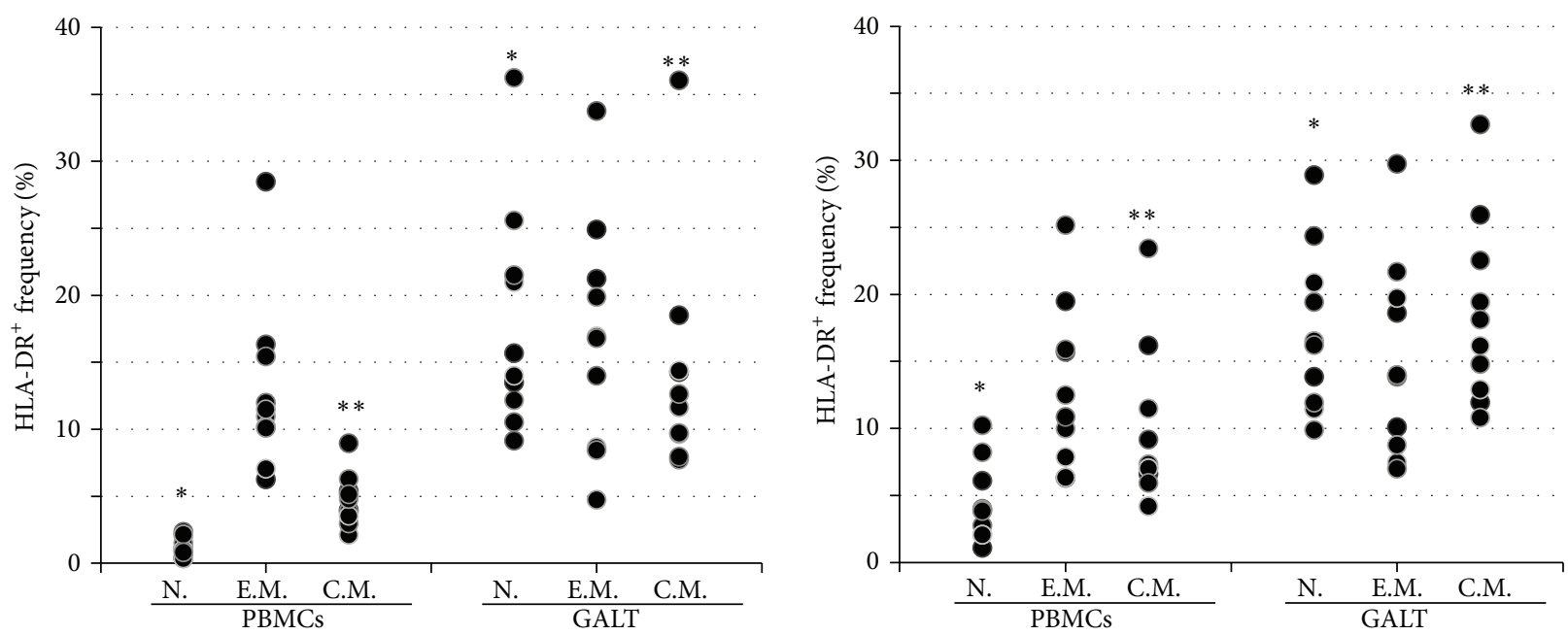

(b)
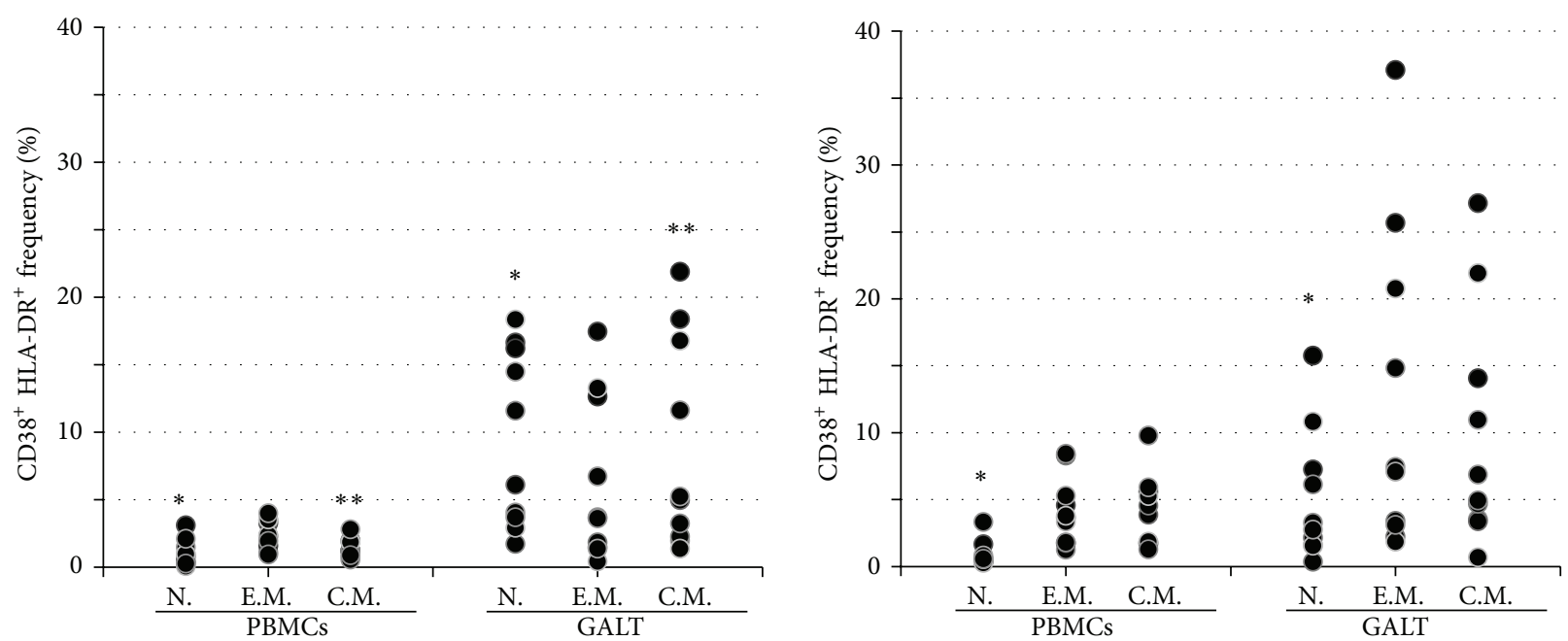

(c)

FIGURE 3: CD38 and HLA-DR expression in lymphocytes subsets derived from peripheral blood mononuclear cells (PBMCs) and gutassociated lymphoid tissue (GALT). Dot plots represent the frequencies of expression of CD38 (Panel (a)) HLA- DR (Panel (b)) and CD38 and HLA-DR (Panel (c)) in naïv (N), effector memory (E.M.), and central memory (C.M.) CD4 $4^{+}$and CD8 ${ }^{+}$in PBMC and in GALT (Wilcoxon test for paired samples $*, * *$, and $* * *=p<0.05)$. 


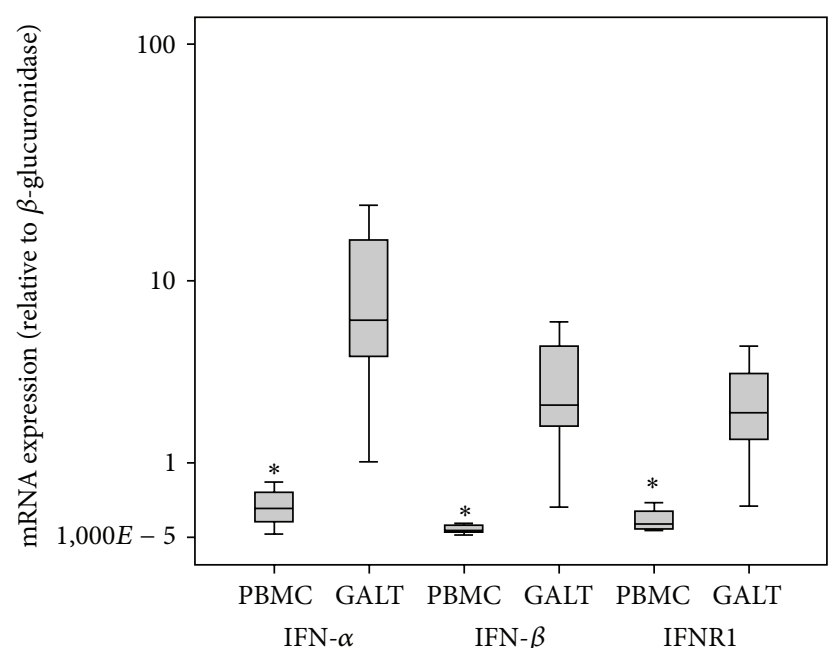

FIGURE 4: Comparison of the levels of interferon (IFN)- $\alpha$, IFN$\beta$, and IFN receptor- (R1-) mRNA in the gut-associated lymphoid tissue (GALT) and peripheral blood mononuclear cells (PBMCs) collected from treated HIV-1-infected patients who had achieved viral load suppression (<37 HIV-1 RNA copies/mL) in response to ART therapy. IFN- $\alpha$ (GALT versus PBMCs) $p=0.01$; IFN- $\beta$ (GALT versus PBMCs) $p=0.01$; IFNR1 (GALT versus PBMCs) $p=0.01$. Wilcoxon test was used to compare IFN- $\alpha$, IFN- $\beta$ and IFNR1 in GALT and PBMC.

0.013, and 15.04 versus 2.94: $p=0.005$, resp.). We also observed that the frequencies of $\mathrm{CD}^{+} \mathrm{T}$ cells expressing HLA-DR antigen were higher in GALT than in peripheral blood (14.31 versus 8.41: $p=0.013$ ); the central memory and naïve $\mathrm{CD}^{+} \mathrm{T}$ subpopulations also expressed more CD38 in GALT compared to that in peripheral blood (17.14 versus 7.19: $p=0.013$, and 16.36 versus 3.87: $p=0.005$, resp.). The naïve $\mathrm{CD}^{+}{ }^{+} \mathrm{T}$ subpopulation coexpressing HLA-DR and CD38 was higher in GALT than in peripheral blood (1.6 versus 0.35 : $p=0.013$ ) (Figure 3).

3.5. Relationship between Type I IFN Activation and the Frequencies of Th1, Tc1, Th17, Tc17, CD4 $4^{+}$, and CD ${ }^{+}$T Cells Activated in Peripheral Blood and GALT Compartments. Next, we evaluated whether there was any relationship between endogenous type I IFN production and the frequencies of naïve and memory Th1/Th17 and Tc1/Tc17 cells and those of $\mathrm{CD}^{+}$and $\mathrm{CD}^{+} \mathrm{T}$ cells expressing HLA-DR, CD38 and coexpressing CD38 and HLA-DR. First, we examined the IFN- $\alpha$, IFN- $\beta$, and IFNR1 gene expression in PBMCs and GALT collected from HIV-1-infected patients who achieved a virological suppression in response to ART. Results indicated that transcript levels of IFN- $\alpha$, IFN- $\beta$, and IFNR1 are extremely variable in both PBMCs and GALT [coefficient of variation $(\mathrm{CV})>100 \%$ ]. However, we found that median values of IFN- $\alpha$, IFN- $\beta$, and IFNR1-mRNAs were, respectively, 21-, 40-, and 16-fold higher in GALT compared to those measured in PBMCs (Figure 4, IFN- $\alpha$ : $p=0.01$; IFN- $\beta$ : $p=$ 0.01 ; IFNR1: $p=0.01)$. A coordinated activation among type I IFN members was observed in GALT as evidenced by the strong correlations between IFN- $\alpha$ and IFN- $\beta$ and between IFNR1 and IFN- $\alpha / \beta$ subtypes (Figures 5(a)-5(c)). By contrast, IFN- $\alpha$ and IFN- $\beta$ were correlated to each other but not to IFNR1 in PBMCs (Figures 5(d)-5(f)). Having observed a highly coordinated expression of type I IFN components in GALT compared to that measured in PBMCs, we evaluated whether there was any correlation between type I IFN activation and the frequencies of naive or memory Th1/Tcl and Th17/Tc17 cell subsets. We observed that IFN$\alpha / \beta$ mRNA levels were negatively related to the frequencies of both IFN- $\gamma$-producing $\mathrm{CD} 4^{+} \mathrm{T}$ and $\mathrm{CD} 8^{+} \mathrm{T}$ naïve cells and also of IFN- $\gamma$-producing $\mathrm{CD}^{+}$memory $\mathrm{T}$ cell subsets (central memory and effector memory) in GALT (Table 3). In addition, negative correlations between the IFNR1 levels and the frequencies of both IFN- $\gamma$-producing $\mathrm{CD}^{+} \mathrm{T}$ naïve cells and the frequencies of IFN- $\gamma$ CD $4^{+}$central memory and $\mathrm{CD}^{+}$effector memory $\mathrm{T}$ cells were also recorded in GALT. By contrast, there was no relationship between type I IFN response and IFN- $\gamma$-producing $\mathrm{CD}^{+}$or $\mathrm{CD}^{+} \mathrm{T}$ cell subsets (naïve, central memory, and effector memory) in the peripheral blood compartment (data not shown). As far as the analysis of the relationship between IFN- $\alpha$, IFN- $\beta$, and IFNR1 production and naive and memory Th17/Tc17 response is concerned, there was no significant relationship between type I IFN activation and Th17/Tc17 response measured in either GALT or peripheral blood compartments (data not shown). Lastly, we evaluated whether there was any correlation between type I IFN expression and the frequencies of $\mathrm{CD}^{+}$and $\mathrm{CD}^{+} \mathrm{T}$ cells expressing HLA-DR, CD38 and coexpressing CD38 and HLA-DR. We found that the amount of IFN- $\alpha(r=0.82, p=0.023)$ and IFN- $\beta(r=0.81$, $p=0.022$ ), but not that of IFNR1, measured in GALT, was correlated with frequencies of $\mathrm{CD} 4^{+} \mathrm{T}$ cells expressing CD38 in peripheral blood. Furthermore, levels of IFN- $\alpha$ and IFN- $\beta$ in peripheral blood were correlated to both the frequencies of CD $4^{+} \mathrm{T}$ cells coexpressing CD38 and HLA-DR (IFN- $\alpha$ : $r=0.96, p=0.0001$; IFN- $\beta: r=0.92, p=0.003)$ and those of $\mathrm{CD}^{+}$effector memory $\mathrm{T}$ cells expressing HLA-DR measured in GALT (IFN- $\alpha: r=0.85, p=0.014$; IFN$\beta: r=0.78, p=0.36)$. Conversely, no relationship was recorded between levels of type I IFN components and the frequencies of $\mathrm{CD}^{+}$and $\mathrm{CD}^{+} \mathrm{T}$ cells expressing HLA-DR, CD38 and coexpressing CD38 and HLA-DR measured in the same compartment (data not shown).

\section{Discussion}

The gut mucosa is known to be a compartment where the interplay between HIV-1 and the host's immune system takes center stage. Therefore, we examined the frequency, phenotype, and functional status of T cell subpopulations in the GALT and peripheral blood of virologically suppressed HIV-1-infected patients on ART therapy, focusing on the IFN- $\gamma$ or $\mathrm{IL}_{-1} 7^{+}$subset of $\mathrm{CD}^{+} \mathrm{T}$ and $\mathrm{CD}^{+} \mathrm{T}$ cells. Throughout the long antiretroviral treatment, we observed a persistent immune activation in GALT expressed by high levels of $\mathrm{CD}^{+} / \mathrm{HLA}-\mathrm{DR}^{+}$and $\mathrm{CD} 4^{+} \mathrm{CD} 38^{+} / \mathrm{HLA}^{-} \mathrm{DR}^{+}$with higher levels of Th17 and Tc17 with respect to peripheral blood. In this regard, it has been reported that gut Th17 cells had a much greater capacity to produce proinflammatory 


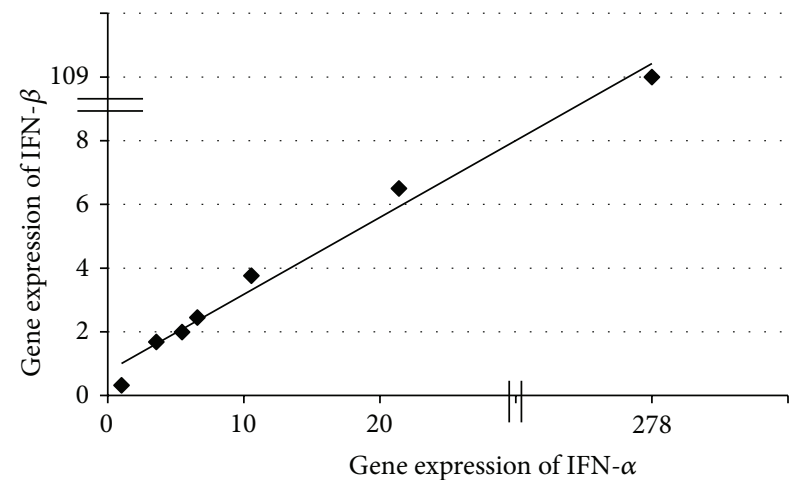

(a)

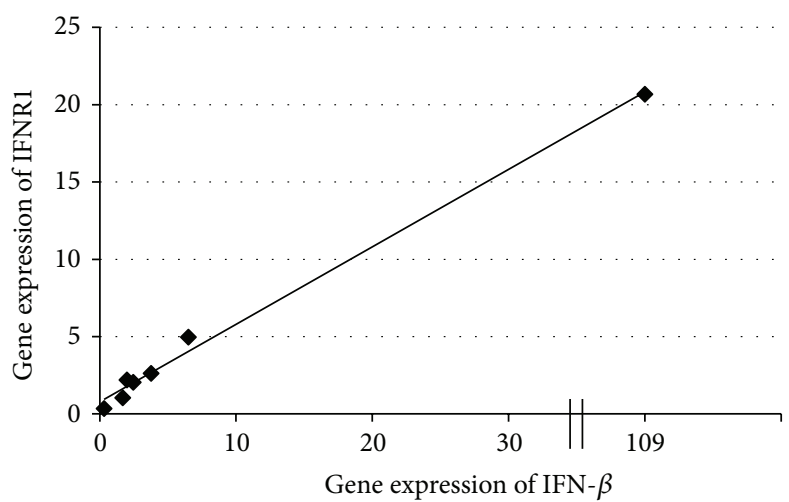

(c)

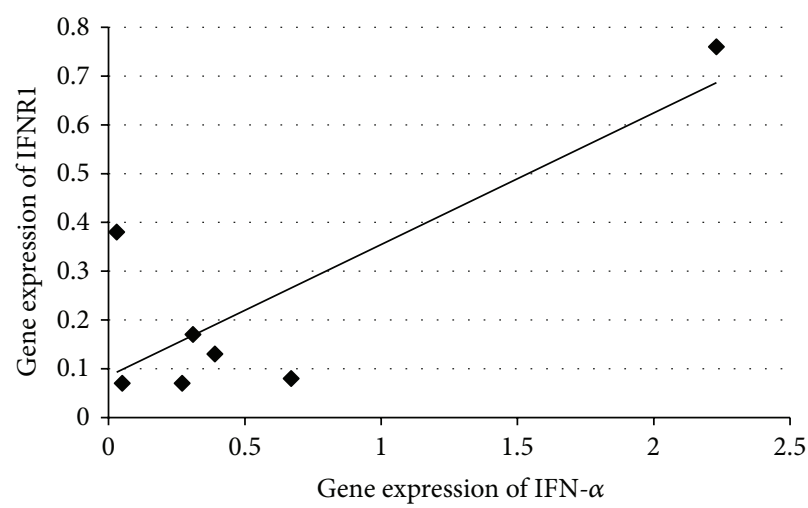

(e)

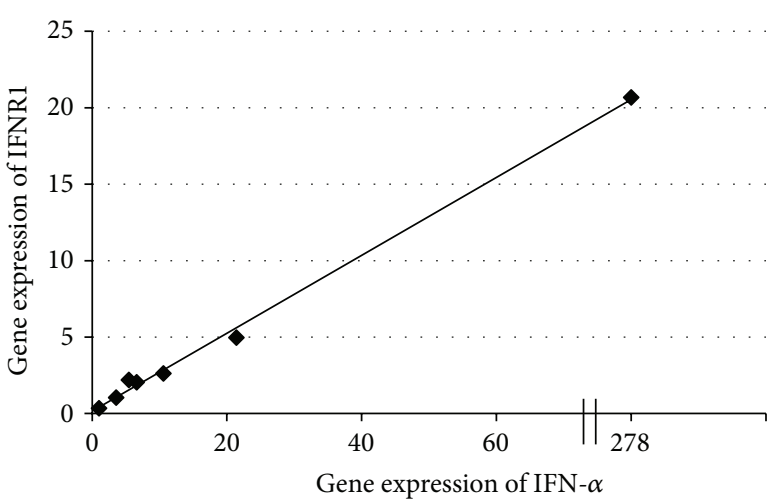

(b)

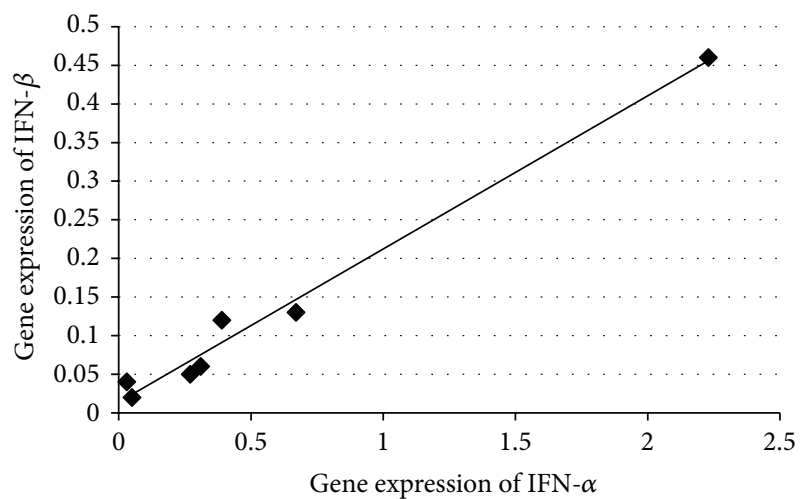

(d)

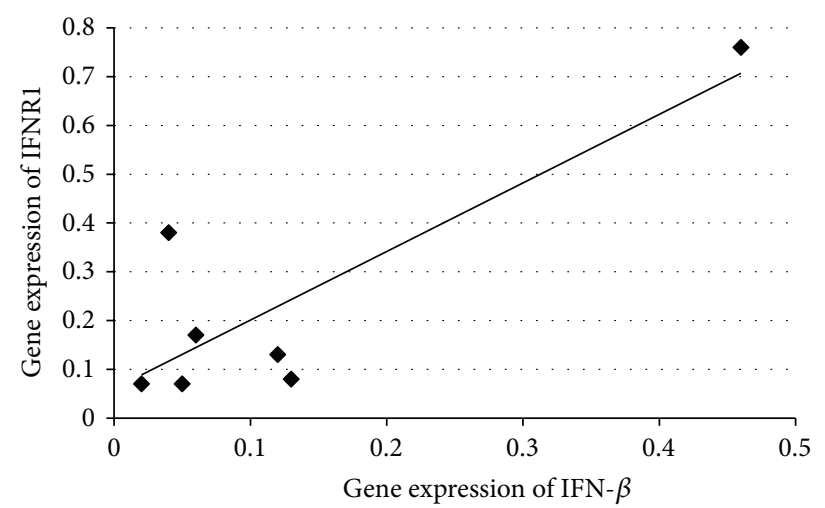

(f)

FIGURE 5: Correlation among type I interferon (IFN) components in the gut-associated lymphoid tissue (GALT) and peripheral blood mononuclear cells (PBMCs) collected from treated HIV-1-infected patients who had achieved viral load suppression $(<37$ HIV-1 RNA copies/mL) in response to ART therapy. GALT: Panel (a), $r=0.98, p<0.001$, [IFN- $\alpha$ versus IFN- $\beta$ ]; Panel (b), $r=0.96, p<0.001$ [IFN- $\alpha$ versus IFN receptor (R1)]; Panel (c), $r=0.96, p<0.001$ [IFN- $\beta$ versus IFNR1]. PBMCs: Panel (d), $r=0.96, p<0.001$ [IFN- $\alpha$ versus IFN- $\beta$ ]; Panel (e), $r=0.32, p=0.48$ [IFN- $\alpha$ versus IFN receptor (R1)]; Panel (f), $r=0.50, p=0.25$, [IFN- $\beta$ versus IFNR1]. Spearman's rho coefficient was used to assess the correlation between type I IFN components in GALT and PBMCs.

cytokines than did those from the blood, but this capacity was dramatically reduced from the earliest stages of HIV infection [15]. Furthermore, Nigam et al. reported that Tc17 and Th17 cells were present in all lymphoid and gastrointestinal tissues studied with predominance in small intestine [16].

Our results also confirm that prolonged antiretroviral treatment improves GALT immune function despite the persistence of immune activation. In this context, we speculate on the importance of discovering new therapeutic strategies that are able to delete immune activation. In fact, the detection of Th17 after PMA stimulation emphasizes that unexhausted cells are present in GALT despite the continuous status of immune activation. Our previous study demonstrated that eight months of ART increased intestinal 
TABLE 3: Analysis of the relationship between type I interferon (IFN) activation and naïve and memory Thl or Tcl cell subsets measured in the gut-associated lymphoid tissue (GALT) of HIV-1-infected patients.

\begin{tabular}{|c|c|c|c|c|c|c|}
\hline & $\begin{array}{c}\text { IFN- } \gamma \mathrm{CD}^{+} \text {naïve } \\
\mathrm{T} \text { cell }\end{array}$ & $\begin{array}{c}\text { IFN- } \gamma \mathrm{CD}^{+} \\
\text {central memory } \mathrm{T} \\
\text { cell }\end{array}$ & $\begin{array}{c}\text { IFN- } \gamma \mathrm{CD}^{+} \\
\text {effector memory } \mathrm{T} \\
\text { cell }\end{array}$ & $\begin{array}{c}\text { IFN- } \gamma \mathrm{CD}^{+} \text {naïve } \\
\text { T cell }\end{array}$ & $\begin{array}{c}\text { IFN- } \gamma \mathrm{CD}^{+} \\
\text {central memory } \mathrm{T} \\
\text { cell }\end{array}$ & $\begin{array}{c}\text { IFN- } \gamma \mathrm{CD}^{+} \\
\text {effector memory } \mathrm{T} \\
\text { cell }\end{array}$ \\
\hline \multirow{2}{*}{ IFN- $\alpha$} & $\mathbf{r}=-0.92$ & $r=-0.71$ & $r=-0.50$ & $\mathbf{r}=-\mathbf{0 . 8 0}$ & $\mathbf{r}=-\mathbf{0 . 8 0}$ & $\mathbf{r}=-\mathbf{0 . 8 9}$ \\
\hline & $p=0.003$ & $p=0.071$ & $p=0.25$ & $p=0.036$ & $p=0.036$ & $\mathbf{p}=\mathbf{0 . 0 0 7}$ \\
\hline \multirow{2}{*}{ IFN- $\beta$} & $\mathbf{r}=-0.92$ & $r=-0.71$ & $r=-0.50$ & $\mathbf{r}=-\mathbf{0 . 8 0}$ & $\mathrm{r}=-\mathbf{0 . 8 0}$ & $\mathbf{r}=-0.89$ \\
\hline & $p=0.003$ & $p=0.071$ & $p=0.25$ & $p=0.036$ & $p=0.036$ & $\mathbf{p}=\mathbf{0 . 0 0 7}$ \\
\hline \multirow{2}{*}{ IFNR1 } & $r=-0.85$ & $r=-0.78$ & $r=-0.57$ & $r=-0.75$ & $r=-0.75$ & $r=-0.85$ \\
\hline & $p=0.014$ & $p=0.036$ & $p=0.18$ & $p=0.052$ & $p=0.052$ & $p=0.014$ \\
\hline
\end{tabular}

*Spearman's rho coefficient was used to assess the correlation between type I IFN activation and naïve and memory Thl or Tcl cell subsets. Significant correlations are highlighted in bold.

$\mathrm{CD}^{+}$and Th17 cells and reduced levels of $\mathrm{T}$ cell activation and proliferation and the magnitude of intestinal $\mathrm{CD} 4^{+} \mathrm{T}$ cell reconstitution correlated with the reduction of plasma LPS [17]. It would be useful to know if Th17 recovered in GALT occurs through routes other than ART. In our opinion, the type I IFN response plays a central role in the pathogenesis of HIV-1 infection both by restricting viral replication and spread and by contributing to chronic immune activation which is currently considered the driving force of acquired immunodeficiency syndrome [18]. This is supported by some degree of correlation found between levels of type I IFN components and the activation of $\mathrm{CD}^{+}$and $\mathrm{CD}^{+} \mathrm{T}$ cells. Thus, to gain new insights into the Thl/Tcl and Th17/Tc17 response in long- term treated HIV-1-infected patients, we also evaluated the expression of IFN- $\alpha$ and IFN$\beta$ and IFNR1 and their relationships with T cell subsets in GALT and peripheral blood compartments. Interestingly, a more vigorous and coordinated IFN- $\alpha / \beta$ and IFNR1 response was observed in mucosal gut compared to that measured in the peripheral blood of HIV-1-infected patients. These findings could indicate an incomplete suppression type I IFN immune activation in GALT despite the long-term therapy, which could be linked to the persisting mucosal viral burden. In agreement with the above observation, Macal et al. demonstrated that long-term therapy could reduce, but not fully suppress, HIV-RNA levels in the gut mucosa, although substantial gut $\mathrm{CD}^{+} \mathrm{T}$ cell restoration was still possible [19]. Limited information is available on the expression of type I IFN pathways in the gastrointestinal tract of HIV-1infected patients. Previous studies examining gene expression responses in GALT to acute-stage and chronic-stage HIV1 infection in ART-naïve patients found a broad increase in IFN-driven immune responses [20-22]. The clinical significance of an upregulation of type I IFN components in GALT compared to the peripheral compartment in long-term treated HIV-1-infected patients remains unknown. However, a significant increase in mucosal gene expression regulating IFN immune activation and inflammation was detected in chronically HIV-1-infected patients with high viral loads but not in long-term nonprogressor patients, supporting the evidence of a detrimental role for IFN $-\alpha / \beta$ during HIV-1 infection [21]. Furthermore, previous studies found a correlation between incomplete mucosal $\mathrm{CD} 4^{+} \mathrm{T}$ cell restoration and increased immune activation in HIV infection despite ART $[19,23,24]$. Here, we observed that IFN $-\alpha / \beta /$ mRNA levels were negatively related to the frequencies of IFN- $\gamma$ producing $\mathrm{CD}^{+} \mathrm{T}$ cell subsets (naïve, central memory, and effector memory) in GALT suggesting that the activation of type I IFN response could have a negative impact on $\mathrm{CD} 8^{+}$ $\mathrm{T}$ cell responses. A negative relationship between type I IFN response and IFN- $\gamma$-producing $\mathrm{CD} 4^{+}$naïve $\mathrm{T}$ cells was also recorded. It is currently unknown whether these negative correlations between type I IFN components and $\mathrm{CD}^{+} \mathrm{T}$ cell subsets and Th1 naïve cells can be considered positive or negative in terms of HIV-1-associated enteropathogenesis. However, it has been reported that viral suppression in longterm nonprogressor patients may result, in part, from efficient maintenance of $\mathrm{CD} 4^{+} \mathrm{T}$ helper and HIV-1-specific $\mathrm{CD} 8^{+} \mathrm{T}$ cell responses in both GALT and circulating lymphocytes [21].

As far as the analysis of type I IFN activation and Th17/Th1 response was concerned, we did not found any relationships between type I IFN activation and Th17/Tc17 response in either compartment analyzed. By contrast, a negative impact of type I IFN on Thl7 differentiation in multiple sclerosis [25] or on the secretion of Th17-polarizing cytokines in human dendritic cells [26] has recently been proposed. However, as a variety of signals can block Th17 commitment including that of IFN- $\gamma$, the highly upregulated type I IFN components in GALT could negatively influence the production of IFN$\gamma$, thereby contributing indirectly to the restoration of Th17 during ART therapy. Further studies are urgently needed to characterize the controversial role of type I IFN in HIV-1 disease and its relationship with IFN- $\gamma$ or IL-17A-producing $\mathrm{CD} 4^{+} \mathrm{T}$ or $\mathrm{CD} 8^{+} \mathrm{T}$ cell subsets in the gastrointestinal tract of HIV-1-infected patients.

All these findings would be greatly strengthened by the evaluation of soluble markers of inflammation (LPS, scCD14, IL-6, and D-dimers) and their correlation with Th17, Th1, Tc17, Tc1 frequencies, and type I IFN components. Another important analysis is the expression of ISGs and other IFN-related genes to better characterize IFN activation pathways in the peripheral blood and GALT compartments of HIV-1 patients. Unfortunately, the material collected in the present study was only enough for the current experiments. 
In conclusion, our comparative investigation of the frequency, phenotype, and functional status of Th1/Tc1 and Th17/Tc17 cell populations in intestinal mucosa and peripheral compartments of long-term HIV-1-infected patients provides new insights into the role of mucosal pathology in HIV-1 disease progression. A significant increase in the gene expression of type I IFN components was detected in GALT compared to peripheral blood. This was negatively related to IFN- $\gamma$-producing $\mathrm{CD}^{+} \mathrm{T}$ cell subsets and also to IFN$\gamma$-producing $\mathrm{CD}^{+}{ }^{+}$naïve $\mathrm{T}$ cells but not to the Th17/Tc17 response. A better understanding of the mucosal relationship between the Th1/Th17 and Tc1/Tc17 axis and antiviral innate defenses during HIV-1 infection will shed more light on the mechanisms of HIV-1 enteropathogenesis.

\section{Conflict of Interests}

The authors declare that there is no conflict of interests.

\section{Acknowledgment}

This work was supported in part by a grant to Carolina Scagnolari from Istituto Pasteur, Fondazione Cenci Bolognetti (Finanziamento dei Programmi di Ricerca 2013-2015, Prot. $55 / 2013)$.

\section{References}

[1] D. Chege, P. M. Sheth, T. Kain et al., "Sigmoid Th17 populations, the HIV latent reservoir, and microbial translocation in men on long-term antiretroviral therapy," AIDS, vol. 25, no. 6, pp. 741749, 2011.

[2] E. J. Ciccone, S. W. Read, P. J. Mannon et al., "Cycling of gut mucosal CD4+ T cells decreases after prolonged anti-retroviral therapy and is associated with plasma LPS levels," Mucosal Immunology, vol. 3, no. 2, pp. 172-181, 2010.

[3] J. Ananworanich, A. Schuetz, C. Vandergeeten et al., "Impact of multi-targeted antiretroviral treatment on gut $\mathrm{T}$ cell depletion and HIV reservoir seeding during acute HIV infection," PLoS ONE, vol. 7, no. 3, Article ID e33948, 2012.

[4] L. Zaffiri, G. d'Ettorre, G. Ceccarelli et al., "Recovery of interleukin-17 production from interleukin-15-stimulated CD4+ mononuclear cells in HIV-1-infected patients with sustained viral suppression," Journal of Interferon and Cytokine Research, vol. 34, no. 1, pp. 35-40, 2014.

[5] J. P. Huber and J. D. Farrar, "Regulation of effector and memory T-cell functions by type I interferon," Immunology, vol. 132, no. 4, pp. 466-474, 2011.

[6] L. E. Harrington, R. D. Hatton, P. R. Mangan et al., "Interleukin 17-producing $\mathrm{CD}^{+}$effector $\mathrm{T}$ cells develop via a lineage distinct from the T helper type 1 and 2 lineages," Nature Immunology, vol. 6, no. 11, pp. 1123-1132, 2005.

[7] A. R. Moschen, S. Geiger, I. Krehan, A. Kaser, and H. Tilg, "Interferon-alpha controls IL-17 expression in vitro and in vivo," Immunobiology, vol. 213, no. 9-10, pp. 779-787, 2008.

[8] B. Guo, E. Y. Chang, and G. Cheng, “The type I IFN induction pathway constrains Th17-mediated autoimmune inflammation in mice," The Journal of Clinical Investigation, vol. 118, no. 5, pp. 1680-1690, 2008.
[9] T. H. Mogensen, J. Melchjorsen, C. S. Larsen, and S. R. Paludan, "Innate immune recognition and activation during HIV infection," Retrovirology, vol. 7, article 54, 2010.

[10] S. K. Pillai, M. Abdel-Mohsen, J. Guatelli et al., "Role of retroviral restriction factors in the interferon- $\alpha$-mediated suppression of HIV-1 in vivo," Proceedings of the National Academy of Sciences of the United States of America, vol. 109, no. 8, pp. 30353040, 2012.

[11] J. P. Huber, H. J. Ramos, M. A. Gill, and J. D. Farrar, "Cutting edge: type I IFN reverses human Th2 commitment and stability by suppressing GATA3," The Journal of Immunology, vol. 185, no. 2, pp. 813-817, 2010.

[12] J. P. Huber, S. R. Gonzales-van Horn, K. T. Roybal, M. A. Gill, and J. D. Farrar, "IFN- $\alpha$ suppresses GATA3 transcription from a distal exon and promotes H3K27 trimethylation of the CNS-1 enhancer in human Th2 cells," The Journal of Immunology, vol. 192, no. 12, pp. 5687-5694, 2014.

[13] J. A. Kovacs, R. A. Lempicki, I. A. Sidorov et al., "Induction of prolonged survival of $\mathrm{CD}^{+}{ }^{+} \mathrm{T}$ lymphocytes by intermittent IL-2 therapy in HIV-infected patients," Journal of Clinical Investigation, vol. 115, no. 8, pp. 2139-2148, 2005.

[14] K. Monteleone, P. Di Maio, G. Cacciotti et al., "Interleukin32 isoforms: expression, interaction with interferon-regulated genes and clinical significance in chronically HIV-1-infected patients," Medical Microbiology and Immunology, vol. 203, no. 3, pp. 207-216, 2014.

[15] C. J. Kim, L. R. McKinnon, C. Kovacs et al., "Mucosal Th17 cell function is altered during HIV infection and is an independent predictor of systemic immune activation," The Journal of Immunology, vol. 191, no. 5, pp. 2164-2173, 2013.

[16] P. Nigam, S. Kwa, V. Velu, and R. R. Amara, "Loss of IL-17producing CD8 $\mathrm{T}$ cells during late chronic stage of pathogenic simian immunodeficiency virus infection," Journal of Immunology, vol. 186, no. 2, pp. 745-753, 2011.

[17] G. d'Ettorre, S. Baroncelli, L. Micci et al., "Reconstitution of intestinal CD4 and Th17 T cells in antiretroviral therapy suppressed HIV-infected subjects: implication for residual immune activation from the results of a clinical trial," PLOS ONE, vol. 9, no. 10, Article ID e109791, 2014.

[18] S. E. Bosinger, Q. Li, S. N. Gordon et al., "Global genomic analysis reveals rapid control of a robust innate response in SIVinfected sooty mangabeys," Journal of Clinical Investigation, vol. 119, no. 12, pp. 3556-3572, 2009.

[19] M. Macal, S. Sankaran, T.-W. Chun et al., "Effective CD4+ T-cell restoration in gut-associated lymphoid tissue of HIV-infected patients is associated with enhanced Th17 cells and polyfunctional HIV-specific T-cell responses," Mucosal Immunology, vol. 1, no. 6, pp. 475-488, 2008.

[20] M. D. George, E. Reay, S. Sankaran, and S. Dandekar, "Early antiretroviral therapy for simian immunodeficiency virus infection leads to mucosal CD4+ T-cell restoration and enhanced gene expression regulating mucosal repair and regeneration," Journal of Virology, vol. 79, no. 5, pp. 2709-2719, 2005.

[21] S. Sankaran, M. Guadalupe, E. Reay et al., "Gut mucosal T cell responses and gene expression correlate with protection against disease in long-term HIV-1-infected nonprogressors," Proceedings of the National Academy of Sciences of the United States of America, vol. 102, no. 28, pp. 9860-9865, 2005.

[22] P. Lerner, M. Guadalupe, R. Donovan et al., "The gut mucosal viral reservoir in HIV-infected patients is not the major source of rebound plasma viremia following interruption of highly 
active antiretroviral therapy," Journal of Virology, vol. 85, no. 10, pp. 4772-4782, 2011.

[23] M. Guadalupe, S. Sankaran, M. D. George et al., "Viral suppression and immune restoration in the gastrointestinal mucosa of human immunodeficiency virus type 1-infected patients initiating therapy during primary or chronic infection," Journal of Virology, vol. 80, no. 16, pp. 8236-8247, 2006.

[24] S. Sankaran, M. D. George, E. Reay et al., "Rapid onset of intestinal epithelial barrier dysfunction in primary human immunodeficiency virus infection is driven by an imbalance between immune response and mucosal repair and regeneration," Journal of Virology, vol. 82, no. 1, pp. 538-545, 2008.

[25] V. S. Ramgolam, Y. Sha, J. Jin, X. Zhang, and S. Markovic-Plese, "IFN-beta inhibits human Th17 cell differentiation," Journal of Immunology, vol. 183, no. 8, pp. 5418-5427, 2009.

[26] X. Zhang, J. Jin, Y. Tang, D. Speer, D. Sujkowska, and S. Markovic-Plese, "IFN- $\beta 1 \mathrm{la}$ inhibits the secretion of Th17polarizing cytokines in human dendritic cells via TLR7 upregulation," Journal of Immunology, vol. 182, no. 6, pp. 39283936, 2009 . 


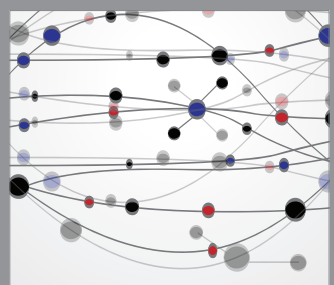

The Scientific World Journal
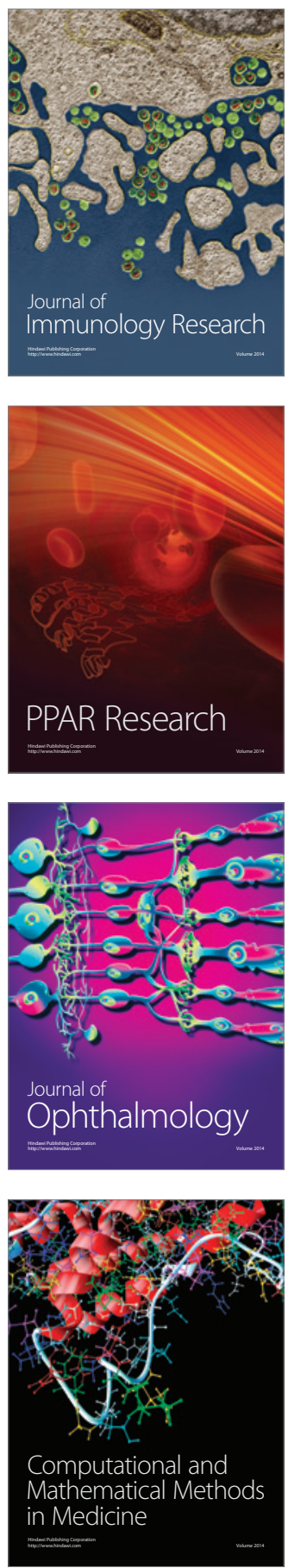

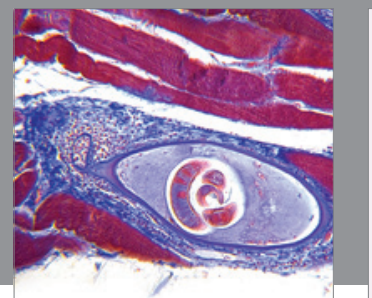

Gastroenterology

Research and Practice
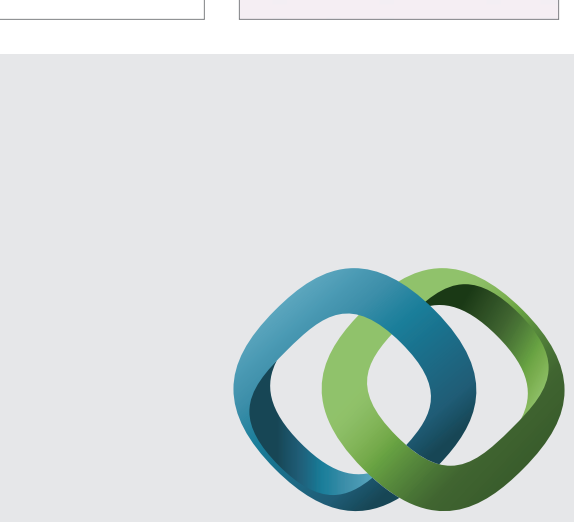

\section{Hindawi}

Submit your manuscripts at

http://www.hindawi.com
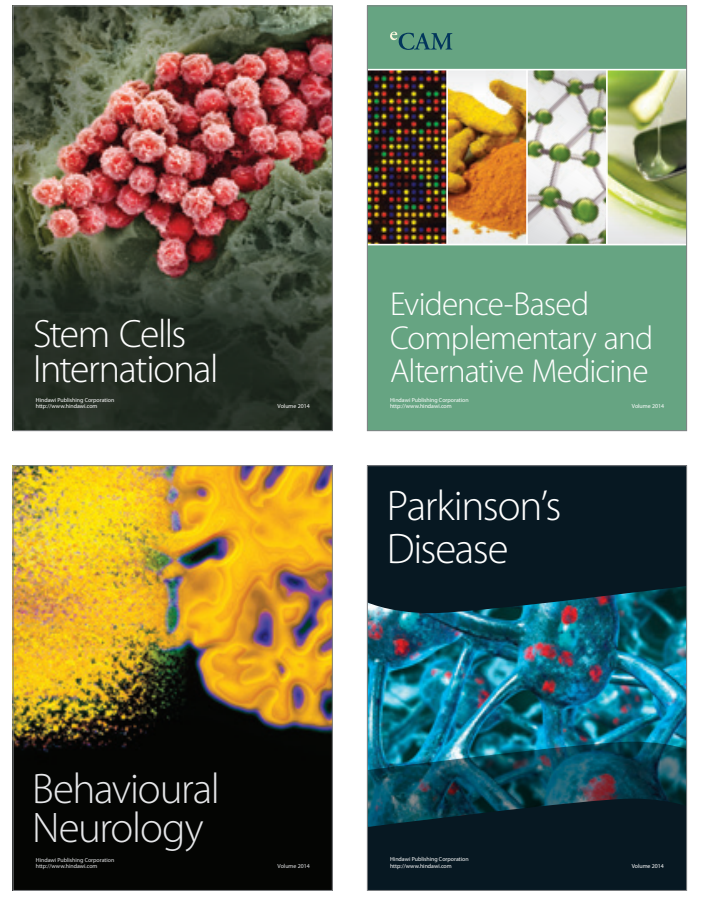
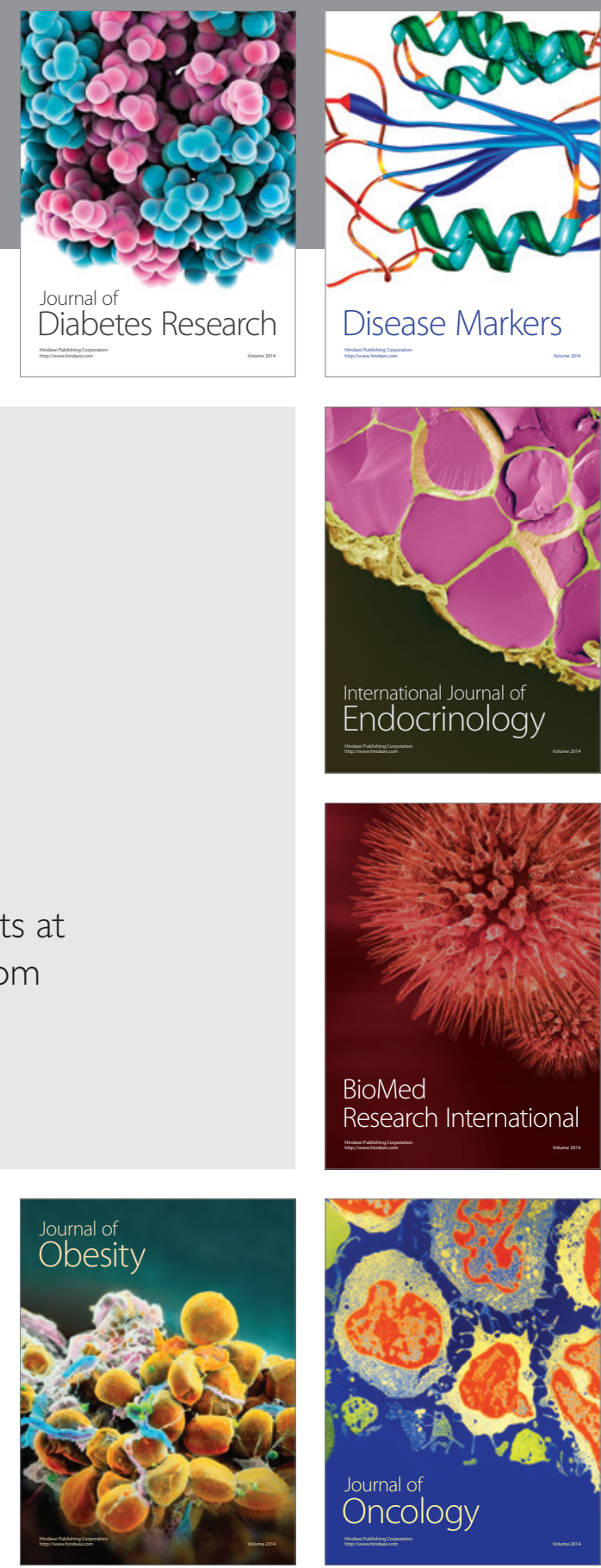

Disease Markers
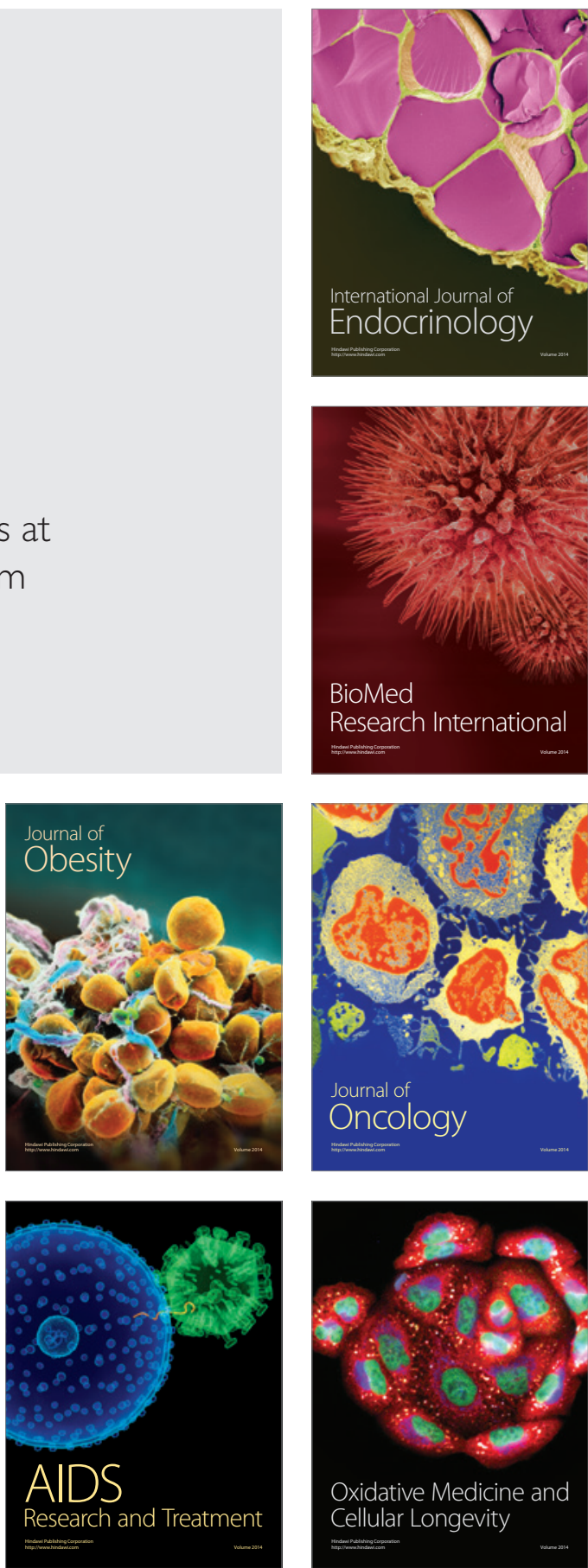